\title{
Effects of County Economy Model on the Rural Youth's Intentions of Urban and Rural Employment in Southwest China:Taking Gongcheng Yao Autonomous County in Guangxi as an Example
}

\author{
Xiaojin Feng* \\ School of Management \\ Hefei University of Technology \\ Hefei, China \\ fengxj168@126.com \\ *Corresponding author
}

\author{
Xuewen Feng \\ Lushan College \\ Guangxi University of Science and Technology \\ Liuzhou, China \\ fengxuewen888@126.com
}

\begin{abstract}
The urban and rural employment psychology and its effect factors in the southern minority areas was analyzed via questionnaire survey. It was found that both the development level and the county economy model affect the youths' employment model and intention which in turn affects the economy development greatly. By taking Gongcheng Yao Autonomous county in Guangxi as an example, in comparison with Quanzhou county in Guangxi, the rural youth's employment intentions as well as the influence were studied. The successful multicultural integration employment mode and the interaction mechanism between the rural youth employment and the county economy development provides a guide for county economy development.
\end{abstract}

Keywords-the southern minority areas; county economy; the rural youth; urban and rural employment

\section{INTRODUCTION}

The scientific development and modernization of agricultural economy and the agricultural structure adjustment creates attractive jobs for the rural youth who stay in hometown. Moreover, county economy is being at the stages of great readjustment and development, especially the county economy in minority areas in China is struggling to catch up with those of the developed areas by attracting great investment from large and medium-sized cities, not only offers the rural youth attractive positions but also exerts great influences on the employment intention. Currently, the "Labors Shortage" that many medium and small enterprises (MEMs) experienced is caused by the competition between county economy and that of big or medium-sized cities'. On March 5, 2011, Premier Wen presented in the Report of Government Work that two balanced means must be put into practice in the measures taken to reform the distribution system in the forthcoming 12th Five Year Plan-one is that the residents' income growth must be perfect cooperation with the economy development, the other is the growth of labor remuneration must be perfect cooperation with the labor productivity. As for the society, it is imperative that providing employment positions increasingly and equal employment opportunity to realize the mentioned means. Also, Premier Wen proposed in the report that "creating jobs should be the priority target during the developments of economy and society, 45 million positions must be created in the following 5years." Obviously, the problem of employment has been referred to the strategy to improve the well-being of the people, and developing county economy would be an important measure. In the county economy development, rural youth are not only the backbone in building the new socialist countryside, but also the main force of the county economy. If young labor move excessively, it will result in relative shortage of labor in rural and county economy, which will in turn be disadvantageous to national economy. Therefore, it is imperative to produce a guidance for rural youth to serve the local economy and to attract the moved labor back via developing county economy [1].

However, what is the relationship between the rural youth's employment intents and county economy? Whether is there a positive correlation between rural youth's employment mode and development mode of county economy? The answers to the questions will pay an important effect to the strategy decision of county economy development. For the questions to be answered well, Gongcheng Yao Autonomous county in Guangxi (denoted as Gongcheng) was taken as a probe to investigate the influences of county economy on the employment intents and types via questionnaire survey, in comparison with Dongshan township of Quanzhou county in Guangxi. Thus, an interactive development between county economy in the southwest and rural youth's employment was proposed.

\section{INVESTIGATION AND ANALYSIS OF RURAL YOUTH' EMPLOYMENT INTENTS IN SOUTHWEST CHINA}

To investigate the influence factors of rural youth's employment and the relationship between rural youth's employment and the development model of county economy, 18 villages from 6 nationality townships located in Quanzhou and Gongcheng counties were chosen as a probe because both Dongshan township and Gongcheng are of comparability with the vast majority Yao residents and the same natural environment and historical conditions while entirely different economy modes. Questionnaire survey was conducted by issuing 800 questionnaires to the rural youth aged from 16 to 35 , withdrawing 620 valid copies. 


\section{A. Basic Economic Data Comparison of Two Tipycal County Economic Development Models}

In southwest China, two typical county economic development models are ecological agriculture and industrialization, respectively. With different models, the rural youth's employment is fairly different. Taking Gongcheng and Quanzhou as examples, rapid development of economy are presented from the 2011 economic data released by the local government (Table I). Although the both counties are located in Guilin, different models have been experiencing since 1980's-ecological agricultural model for Gongcheng and traditional agricultural model for Quanzhou. Gongcheng was formerly one of the poorest counties in China, however, it's economy and society have been entering a rapid development stage since 1990's. And not only its GDP but also the fixed investment, value-added of industry, and the total sales of social consumer goods have exceeded those of Quanzhou in 2011 according to the calculated per capita. At the same time, both foreign investments and the agricultural product processing industry have stimulated the agricultural dimensions, the industrializations, and the tertiary industry. The tourism and foreign capital utilization in Gongcheng are now two great advantages over Quangzhou. It can be seen that the employments of the rural residents in two counties are different from each other, especially the youth. In Quanzhou, young migrant workers account for more than $90 \%$, and what's more the rural youth have almost migrated in remote villages. On the contrary, the youth in Gongcheng engage in kinds of occupations in either the county or the villages.

TABLE I. 2011 ECONOMIC DATA COMPARISON BETWEEN QUANZHOU AND GONGCHENG

\begin{tabular}{|c|c|c|}
\hline County & Gongcheng & Quanzhou \\
\hline Population / ten thousand & 28.5 & 78 \\
\hline Per capita GDP / CNY & 24532 & 19232 \\
\hline primary industry / \% & 29.13 & 29.97 \\
\hline secondary industry / \% & 42.96 & 46.16 \\
\hline tertiary industry / \% & 27.92 & 23.87 \\
\hline
\end{tabular}

a. From the 2011's Guangxi statistical yearbook

\section{B. Comparison of the Rural Youth'S Employment Intentions of the Mentioned Counties}

According to the features of county economy and the youth's typical employment, six employment types of farming in hometown, planting and breeding, working in county, carving out, serving as a leader, and developing one's careers in big cities are devised to investigate the youth's employment intentions as demonstrated in Fig.1. It reveals from the 620 copies of valid questionnaire that the rural youth's employment intentions are quite different except the same selection that very few youth would like to stay at home for traditional farming. In Dongshan township of Quanzhou, most youth expect to migrate to big cities for better jobs or serve as local leaders__among which $59.1 \%$ expect to migrate to big cities and $16.7 \%$ to work in official institutions or administrative departments, leaving a few people wishing to carve out $(8.3 \%)$, work in county $(5.6 \%)$, plant and breed $(5.1 \%)$. Obviously, the rural youth prefer migrating for jobs to working in the county or their village.
However, except farming in hometown, the proportions of the others are reasonable, with $21 \%$ of the youth expecting migrating to big cities, indicating that most rural youth would prefer to participate local economy constructions. The differences are correlated with their economic development models. As for Quanzhou, it is industrially dominant. Thus, the rural youth would like to hunt for better jobs in big cities as they have no advantages over their competitors and there isn't a good atmosphere for planting and breeding there. As for Gongcheng, on the contrary, it has experienced an ecological agriculture that planting fruit trees and breeding are adopted to be efficient measures to increase income since 1980's. Hence the excellent atmosphere of entrepreneurship is responsible for the great attractions of local youth to participate in the county economy development.

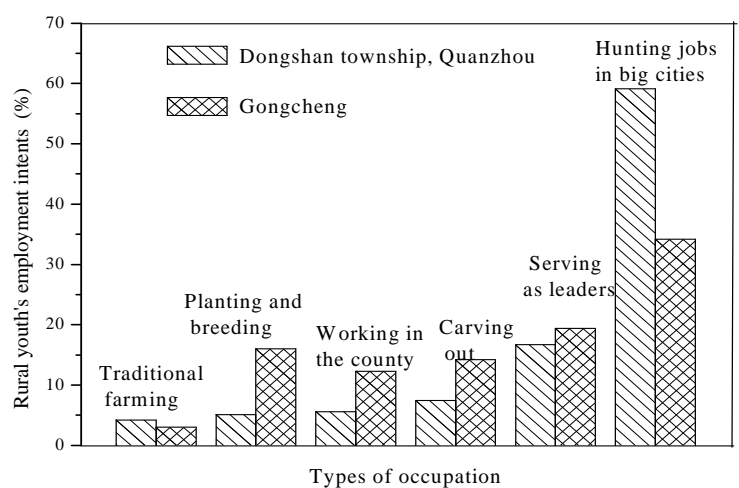

Fig.1 The rural youth's employment intentions as a function of different types of occupations (Serving as leaders means working in official institutes or administrative departments and carving out means operating stores or agricultural agents)

\section{Factors that Affect the Employment Intentions of the Rural Youth in Southwest China}

To investigate the factors that affect the employment intentions of the rural youth in Southwest China, three career criterions of income, social equality, and personal development are chosen, during which individual features of age, gender, and education level are also considered (Table II). The results reveal that different investigation indexes affect the employment intention distinctly. First, the feature of gender has modest effect except carving out, which correlates with the traditional farming culture and the men's nature of positive challenging. Second, education level would also affect the intention greatly. The rural youth with university degree prefer to serve as leader or digging in big cities. Those with senior high education would like to work in their county or plant and breed, which accords with the results [2]. Compared with the other occupations, those with junior high education prefer to planting and breeding or working in the county or big cities. Most of those involving in traditional farming are with junior high education. Third, the feature of age would also have great effects on the rural youth's employment intentions_— those aged from 16 to 25 prefer to serve as leader or digging in big cities, while a higher proportion would like to work in the county, carve out, or plant and breed for those aged from 26 to 35 due to their fewer experiences, poorer economy, and less education. Fourth, the youth currently emphasize the careers that are 
with better economic returns, equal footing, and promising. Most of them hold a negative attitude towards the equality in big city, and thus serving as leaders, carving out, working in the county, and planting and breeding are their preferential choices instead of earning money and/or accumulating experiences in big city.

TABLE II. FACTORS THAT INFLUENCE RURAL YOUTH'S EMPLOYMENT INTENTIONS

\begin{tabular}{|c|c|c|c|c|c|c|c|c|c|c|}
\hline \multirow{2}{*}{$\begin{array}{l}\text { Sample feature } \\
\text { employment } \\
\text { Intents }\end{array}$} & \multicolumn{2}{|c|}{ Gender } & \multicolumn{3}{|c|}{ Educational level } & \multicolumn{2}{|c|}{ age } & \multicolumn{3}{|c|}{ Career criterions } \\
\hline & male & female & Junior & $\begin{array}{c}\begin{array}{c}\text { Senior or } \\
\text { technical } \\
\text { school }\end{array} \\
\end{array}$ & University & $16-25$ & $26-35$ & $\begin{array}{l}\text { Economic } \\
\text { returns }\end{array}$ & $\begin{array}{c}\text { Equal } \\
\text { footing }\end{array}$ & $\begin{array}{l}\text { Individual } \\
\text { progress }\end{array}$ \\
\hline Serving as leaders & 0.48 & 0.52 & 0.08 & 0.27 & 0.65 & 0.74 & 0.26 & 0.93 & 0.85 & 0.47 \\
\hline Carving out & 0.75 & 0.25 & 0.17 & 0.38 & 0.45 & 0.41 & 0.59 & 0.93 & 0.78 & 0.80 \\
\hline Digging in big cities & 0.49 & 0.51 & 0.22 & 0.33 & 0.45 & 0.63 & 0.37 & 0.97 & 0.13 & 0.88 \\
\hline Working in the county & 0.47 & 0.53 & 0.30 & 0.50 & 0.20 & 0.34 & 0.66 & 0.34 & 0.88 & 0.11 \\
\hline Traditional farming & 0.52 & 0.48 & 0.76 & 0.24 & 0.00 & 0.24 & 0.76 & 0.00 & 0.95 & 0.05 \\
\hline Planting and breeding & 0.52 & 0.49 & 0.38 & 0.50 & 0.12 & 0.31 & 0.69 & 0.87 & 0.80 & 0.59 \\
\hline
\end{tabular}

\section{EMPIRICAL ANALYSIS}

\section{A. Effects of County Economy Development Patterns on the Rural Youth'S Employment Intentions in Southwest China}

In minority areas in Southwest China, the employment model are tremendously different. In the areas with better economy, the occupation distribution are relatively reasonable. However, in those with poorer economy, the prior intention is working in big city, then those with steady income. Obviously, the different models of county economy are responsible for the various intentions. In Quanzhou, industry and service are chosen preferentially for economy development. And the youth questionnaire are located in the remotest township of Quanzhou's, their main income depends on the migrating working, because industrialization and modern agriculture are far away from the villages. Moreover, although the three major readjustments of industrial structure are consciously optimized, they have poorly positive effects on the youth's employment. Hence, the youth engaging planting in large scale and scientific breeding are rare. However, the opposite phenomena occur in Gongcheng because it experiences ecological development pattern. The ecological pattern not only promotes the industries such as planting in large scale and scientific breeding, ecological tourism, food processing industry, transportation, packing and marketing of agricultural products, but also benefits the service industry. Therefore, the youth there choose to carve out, to engage in the relative occupations, or to migrate for hunting better opportunities according to their own abilities.

\section{B. The Career Phycology of the Rural Youth in Minority Areas in South China Featuring the Yao Minority'S}

The career psychology of the rural youth is deeply branded with the Jumping Carps that one can acquire good job instead of farming on native land via receiving better education. Affected by the tradition of "a learned person should become an official and serve the country", the Yao people emphasize cultivating their further generations extremely since ancient times because they have experienced poverty, backwardness, and hardship. The rural youth desire for power and money greatly. That is why the jobs with steady income are their preferential choice. The questionnaire survey reveals that $20 \%$ of the rural youth prefer to serve as national public servant or official staff which can receive better income and promotion. The rural young men and women show the same interest in all the occupations due to the industrious and prosperous traditions among the Yao people except carving out.

\section{The Important Effects of Individual Quality on the Rural Youth'S Career Choice}

620 samples, among which $90 \%$ received junior high education, are chosen to examine the effect of individual quality on the rural youth's career choice. Most prefer to serve as national public servant, carving out, and developing in big cities, which correlates with not only the demand of high-quality talents in modern society of knowledge economy but also the civil servant tide in China. Those received high educations desire for rich experiences and realization of self-worth, demonstrating that they can incorporate the urban life more easily. Those with junior high education prefer to migrate for jobs or plant and breed due to their less education which in turn limits the opportunity of serve as national public servant. However, compared with those with junior high education, those with senior high education would prefer to hunt job near their hometown because of higher opportunity cost of the labor migration [2].

Furthermore, the rural youth's employment intentions are also affected by their experiences and economic foundation. The youth aged 25 and above would prefer to entrepreneurial employment instead of working in big cities or national public servant due to their richer experience and stronger economic foundation. As for those aged from 16 to 25 , they prefer serving as official and working in big cities because of better promotion opportunity and easier realization of selfworth.

\section{The Emphasization of Personal Career Development and Realization of Self-Worth}

In modern society, the rural youth emphasize personal development, equal rights, and realization of self-worth although income is still a guidance. It is considered that serving as official, carving out, planting and breeding, and working in the local county can achieve equal rights and realization of self-worth. However, $87.2 \%$ of those who choose to dig in big cities are attracted by the opportunities to get better income or individual progress instead of equal rights. When the income is close, they would prefer to work near their hometown due to the existence of rural-urban dual structure which prevent them from social pension, basic medical care, and unemployment insurances. And the pay 
gap makes them feel further unfair. That's why it became a fairly hot topic when the proposal "The Government committed in its Report of Government Work to do everything to ensure that the Chinese people live a happier life with more dignity" was originated. Also, it is a powerful measure to deal with Chinese "Shortage of Labor" that how to enable the migrant workers feel equality and justice.

\section{POLICY SUGGESTIONS}

\section{A. Developing County Economy Relying on the Local Advantage Resources is the Scientific Option to Create Jobs for the Rural Surplus Labor in Minority Areas}

Although minority areas are relatively remote, with adverse climate, there are usually plenty of mineral resources and ethnic characteristics cultures. To improve the rural residents' situation, increase their income fundamentally, and raise the happiness index, it is not enough to migrate the rural youth simply because the dualistic household register management system that divides urban and rural areas is still no fundamental improvement. Hence there are many problems and difficulties in the process of migrated peasant's citizenship especially for the rural youth because they received better education, desire for democracy and equity more strongly than their parents. Thus, developing county economy relying on the local advantage resources is considered to be the preferential method to create more positions and pioneering opportunities, improve the abilities, and increase their income[3].

\section{B. Developing the Rural Human Resource and Improving the Rural Youth'S Abilities to Employ and Carve out}

In minority areas, rural youth are the elite in county economy construction. It's the key to solve the employment problem that developing the economy and improving the bearing capacity of labor in urban and rural areas. However, the youth there are usually received poorer educations than those in faster developing areas, the essential way to solve the employment problem is to improve themselves via human resource investment, which in turn results in better jobs and income. From the perspective of county economy, it's imperative to set up talent pool aiming to the features of countryside and modern agriculture. For those youth working or carving out in one's own hometown, it's very important to provide technical training, operating and management training, and market risk profile.

\section{Perfecting Market and Competitive Mechanisms of Human Resource Gradually, Improving the Rural Youth'S Employment Fairly}

Currently, there are many flaws in the employment market in China and uniform administrative standards of labor employment have not established yet in medium-sized and small enterprises. When the rural youth migrate for jobs, no wage standard is abided by or Labor Laws are executed strictly. With the development of society, the education investment in countryside has been increasing continually, thus the Cenozoic migrant workers have improved their sense of defending their own rights and legal quality, which aggravates Chinese Shortage of Labor. Therefore, promoting the job-hunting opportunity equally has attracted much attention. Perfecting the human resource market can not only achieve fair employment but also improve the rural youth's comprehensive quality.

\section{Establishing the Social Security of the Urban and Rural Integration, Getting Rid off the Migrant Workers' Extra Worries}

The social security system in China are mainly implemented based on the household registration system. Although some enterprises have taken out kinds of insurances for their migrant workers, most insurances are still restricted by the household registration system. For instance, the medical insurance is currently restricted by the household registration system, once the migrated workers get ill, the difficulties will be hard to be measured. Another is the children's enrolment. Although some schools for children of employees are built in some cities, the educational resources are much weaker than those of public schools. If they want to receive education right in the school district, the enrolment is quite complex. That's why poor satisfactions about migrating for jobs in big cities are evaluated. Therefore, establishing the social security system of integrating rural areas into urban ones is not only the way to get rid of the extra worries, but also the efficient measure for the rural residents to be citizenized.

\section{CONCLUSIONS AND PROSPECTS}

With the economic and social development, the rural youth desire for higher quality life, better career, more satisfied realization of self-worth, and social equality. If the income is equal or close, they would prefer to those occupations with more social equality and more satisfied realization of self-worth. Thus, as for county economy development, "Gongcheng Pattern"[4] is deserved to be taken as a guidance to create jobs without preventing the requirement of rural labor from local economy development.

The 12th Five Year Plan brings new chances and challenges for Southwest China. It is the rural youth's migration to big and medium-sized cities that results in the Shortage of Labor for the county economy development. Hence, developing the local economy relying on the advantageous resources can not only realize modernization and dimensions of agriculture, but also prosper modern industry and ternary industry. Furthermore, it has become the spirit of the times by attracting the migrated rural youth back via providing more opportunities and more attractive jobs to promote the development of county economy.

\section{REFERENCES}

[1] Q. Zheng, L. Zhao, "Study on migrant workers' job-hunting tendency and its influence factors, " Rural economy. Issue 4, 2006

[2] J. Rong, "Rural youth's human capital investment in China: Education or migration?" Youth Study. Issue 3, 2008

[3] Y. Zhen, W. Chen, and L. Ge, "Analysis of intergenerational differences of migrant workers' employment psychology ," Journal of Hangzhou University of Electronic Science and Technology (Social science edition), issue 12, 2007

[4] Z. Luo, Ecological poiverty alleviation and development and the integration of urban and rural areas-Gongcheng Model and its evalution, Beijing: The Publishing House Of Economic Science, 2010 